\title{
Factors associated with Health-Related Quality of Life in Kidney Transplant Recipients in France
}

\author{
Yosra Mouelhi ${ }^{1 *}$, Elisabeth Jouve ${ }^{2}$, Marine Alessandrini ${ }^{1}$, Nathalie Pedinielli ${ }^{2}$, Valérie Moal ${ }^{3}$, Aurélie Meurette ${ }^{4}$, \\ Elisabeth Cassuto ${ }^{5}$, Georges Mourad ${ }^{6}$, Antoine Durrbach$^{7}$, Bertrand Dussol ${ }^{3}$ and Stéphanie Gentile ${ }^{1,2}$
}

\begin{abstract}
Background: Health-Related Quality of Life (HRQoL) assessment after kidney transplantation has become an important tool in evaluating outcomes. This study aims to identify the associated factors with HRQoL among a representative sample size of Kidney Transplant Recipients (KTR) at the time of their inclusion in the study.

Methods: Data of this cross-sectional design is retrieved from a longitudinal study conducted in five French kidney transplant centers in 2011, and included KTR aged 18 years with a functioning graft for at least 1 year. Measures include demographic, psycho-social and clinical characteristics. To evaluate HRQoL, the Short Form-36 Health Survey (SF-36) and a HRQoL instrument for KTR (ReTransQol) were administered. Multivariate linear regression models were performed.

Results: A total of 1424 patients were included, with $61.4 \%$ males, and a mean age of 55.7 years $( \pm 13.1)$. Demographic and clinical characteristics were associated with low HRQoL scores for both questionnaires. New variables were found in our study: perceived poor social support and being treated by antidepressants were associated with low scores of Quality of Life (QoL), while internet access was associated with high QoL scores.

Conclusion: The originality of our study's findings was that psycho-social variables, particularly KTR treated by antidepressants and having felt unmet needs for any social support, have a negative effect on their QoL. It may be useful to organize a psychological support specifically adapted for patients after kidney transplantation.
\end{abstract}

Keywords: Cross sectional, Health-related quality of life, Kidney Transplant Recipients, ReTransQol, SF-36

\section{Background}

In public health and medicine, Health-Related Quality of Life (HRQoL) measurements have become an important outcome measure in addition to morbidity and mortality rates, both in population health assessment and in clinical trials $[1,2]$. HRQoL is a multi-dimensional concept that includes domains related to physical, mental, emotional, and social functioning. It goes beyond direct measures of population health, life expectancy and causes of death, and focuses on the impact that health status has on Quality of Life (QoL) [2]. In addition to its multidimensional nature, one important reason to measure the

\footnotetext{
* Correspondence: yosra.mouelhi@ap-hm.fr

${ }^{1}$ Laboratoire de Santé Publique, Faculté de Médecine, Université

Aix-Marseille, 3279 Marseille, EA, France

Full list of author information is available at the end of the article
}

HRQoL is establishing and expanding information about the range of problems that affect the patients [3-5].

In general, chronic diseases are increasingly widespread [6]. The World Health Organization (WHO), therefore, prioritizes HRQoL improvement for people living with chronic diseases [7]. In France, the August 9, 2004 public health law applied this priority, implementing a national plan to improve the HRQoL for people living with chronic diseases, mainly those with EndStage Renal Disease (ESRD) [8]. The French Biomedicine Agency and the National Institute for Public Health Surveillance have promoted studies to determine the level of HRQoL of ESRD patients in France in order to improve the HRQoL of chronic disease patients $[9,10]$.

When compared with dialysis, renal transplantation has become the most cost-effective treatment [11-13]

(c) The Author(s). 2018 Open Access This article is distributed under the terms of the Creative Commons Attribution 4.0 International License (http://creativecommons.org/licenses/by/4.0/), which permits unrestricted use, distribution, and reproduction in any medium, provided you give appropriate credit to the original author(s) and the source, provide a link to the Creative Commons license, and indicate if changes were made. The Creative Commons Public Domain Dedication waiver (http://creativecommons.org/publicdomain/zero/1.0/) applies to the data made available in this article, unless otherwise stated. 
Table 1 Patients' characteristics $(N=1424)$

\begin{tabular}{|c|c|}
\hline & N (\%) \\
\hline \multicolumn{2}{|l|}{ Gender } \\
\hline Male & $874(61.4)$ \\
\hline \multicolumn{2}{|l|}{ Age (years) } \\
\hline Mean \pm SD & $55.7 \pm 13.1$ \\
\hline Range & $18.8-85.9$ \\
\hline \multicolumn{2}{|l|}{ Level of education } \\
\hline Primary or less & $163(11.5)$ \\
\hline College & $536(37.9)$ \\
\hline Secondary 1st stage & $304(21.5)$ \\
\hline University & $413(29.1)$ \\
\hline \multicolumn{2}{|l|}{ Living arrangement } \\
\hline Alone & $323(22.7)$ \\
\hline \multicolumn{2}{|l|}{ Children } \\
\hline No children & $390(27.6)$ \\
\hline \multicolumn{2}{|l|}{ Employment status } \\
\hline Employed & $548(38.5)$ \\
\hline Retired & $545(38.3)$ \\
\hline Unemployed & $329(23.2)$ \\
\hline Patients receiving disability pension & $487(34.7)$ \\
\hline \multicolumn{2}{|l|}{ Monthly incomes in the household $(€)$} \\
\hline$<739$ & $100(7.5)$ \\
\hline $740-1200$ & $255(19.1)$ \\
\hline $1201-2200$ & 419 (31.4) \\
\hline $2201-4400$ & $425(31.8)$ \\
\hline$>4400$ & $136(10.2)$ \\
\hline \multicolumn{2}{|l|}{ Internet } \\
\hline Patients with Internet use & $1131(79.9)$ \\
\hline Patients with Social networks use & $417(36.9)$ \\
\hline \multicolumn{2}{|l|}{ Perceived social support } \\
\hline Patients in need for an esteem support & $869(61.1)$ \\
\hline Patients in need for a financial support & $377(26.5)$ \\
\hline Patients in need for an informative support & $559(39.4)$ \\
\hline Patients in need for an emotional support & $592(41.8)$ \\
\hline
\end{tabular}

$S D$ standard deviation

for ESRD patients, as it presents medical costs reduction, extended lifetime [14] and enhanced HRQoL $[11,15,16]$.

Although the HRQoL advantages in Kidney Transplant Recipients (KTR) were established [11, 14, 16-21], life after kideny transplantation may present negative as well as positive aspects. Therefore, it is essential to describe the demographic and clinical factors that influence HRQoL outcomes. Furthermore, most published studies did not clearly explore the psycho-social variables that potentially can affect the QoL. This study aims to identify factors associated with HRQoL through a comprehensive analysis of demographic, psycho-social and clinical characteristics among a representative cohort of KTR living in France.

\section{Methods}

\section{Study design and patients}

This is a cross-sectional design retrieved from a longitudinal study carried out continuously during the year 2011, in five French kidney transplant centers: Marseille, Montpellier, Nice, Paris and Nantes University Hospitals. All patients aged 18 years and older with a functioning graft for at least one year were eligible for the study. Multi-organ transplant patients before or simultaneously with their kidney transplant were excluded.

\section{Data collection and measures}

Patients were included in 2011 during their regular medical visits. Data of inclusion, including demographic, psycho-social characteristics and HRQoL, were directly collected from the patients who agreed to participate, except health data which were obtained from nephrologists.

\section{Demographic and psycho-social characteristics}

Demographic and psycho-social variables collected were: $>$ Age, gender, level of education: primary or less, college, secondary 1st stage and university

$\triangleright$ Living arrangement: alone or not alone

$>$ Having children or not, employment status: employed, retired, unemployed

$>$ Disability pension: patients receiving disability pension or not

$\triangleright$ Monthly incomes in the household $(€)$

$>$ Internet and social network use

$>$ Social support: done by a perceived questionnaire, used to estimate the availability and the quality of this support [22]. It is composed of four main scales: esteem, financial, informative and emotional supports. For each scale, patients were asked to answer if they were in need for this support or not.

\section{Clinical characteristics}

Medical measures were grouped into four domains related to kidney disease, health status and comorbidities, treatments (i.e. drugs) along with their side effects and biological data.

1. To explore kidney disease: we collected the etiology of End-Stage Renal Disease (ESRD), the previous dialysis treatment and duration, the duration since transplantation, the organ donor type (cardiac death, deceased or living-related donor), the organ transplantation (one or two simultaneous kidney 
Table 2 Clinical characteristics: kidney disease, health status, comorbidities and biological data

\begin{tabular}{|c|c|}
\hline & $N(\%)$ \\
\hline \multicolumn{2}{|l|}{ Major causes of ESRD } \\
\hline Chronic glomerulonephritis & $487(34.3)$ \\
\hline Interstitial nephropathy & $158(11.3)$ \\
\hline Polycystic kidney disease & $262(18.8)$ \\
\hline Other nephropathies (vascular, diabetic...) & $497(35.6)$ \\
\hline \multicolumn{2}{|l|}{ Previous dialysis treatment } \\
\hline Patient with dialysis treatment & $1212(86.8)$ \\
\hline $\begin{array}{l}\text { Duration of dialysis, Median (25th percentiles, 75th } \\
\text { percentiles) }\end{array}$ & $24(12,42)$ \\
\hline \multicolumn{2}{|l|}{ Transplantation } \\
\hline $\begin{array}{l}\text { Duration of transplantation, Median (25th percentiles, } \\
\text { 75th percentiles) }\end{array}$ & $7.1(3.7,12.8)$ \\
\hline \multicolumn{2}{|l|}{ Organ donor type } \\
\hline Cardiac death donor & $47(3.4)$ \\
\hline Deceased donor & $1231(88.3)$ \\
\hline Living-related donor & $116(8.3)$ \\
\hline Organ transplantation & $1396(98.0)$ \\
\hline Only one kidney graft & $1373(98.4)$ \\
\hline Two simultaneously kidney grafts & $23(1.6)$ \\
\hline \multicolumn{2}{|l|}{ Kidney Transplants number } \\
\hline The first transplant & $1199(85.7)$ \\
\hline The second transplants & $181(12.9)$ \\
\hline Three or more transplants & $19(1.4)$ \\
\hline Patients with at least one acute rejection episode & $213(15.3)$ \\
\hline Patients with chronic graft dysfunction & $426(30.6)$ \\
\hline \multicolumn{2}{|l|}{ Comorbidities } \\
\hline Neoplasia & $285(20.4)$ \\
\hline Hypertension & $1143(81.8)$ \\
\hline Diabetes mellitus & $255(18.2)$ \\
\hline Smoking patients & $203(14.9)$ \\
\hline $\mathrm{BMI}>30\left(\mathrm{~kg} / \mathrm{m}^{2}\right)$ & $213(15.3)$ \\
\hline \multicolumn{2}{|l|}{ Karnofsky Index scale, rating criteria (\%) } \\
\hline 80-100: Able to carry on normal activity and to work & $1311(94.2)$ \\
\hline 50-70: Unable to work & $76(5.5)$ \\
\hline 20-40: Unable to care for self & $3(0.2)$ \\
\hline 0-10: Death, disease may be progressing rapidly & $2(0.1)$ \\
\hline \multicolumn{2}{|l|}{ Charlson Comorbidity Index, score } \\
\hline Mean \pm SD & $4.09 \pm 1.8$ \\
\hline Range & $2-14$ \\
\hline \multicolumn{2}{|l|}{ Biological data } \\
\hline \multicolumn{2}{|l|}{ Creatinine levels ( $\mu \mathrm{mol} / \mathrm{L})$} \\
\hline Normal: < 120 & $583(42.6)$ \\
\hline Mild to moderate: $120-250$ & $697(50.8)$ \\
\hline Severe: > 250 & $91(6.6)$ \\
\hline
\end{tabular}

Table 2 Clinical characteristics: kidney disease, health status, comorbidities and biological data (Continued)

\begin{tabular}{ll}
\hline & $\mathrm{N}(\%)$ \\
\hline Hemoglobin levels $(\mathrm{g} / \mathrm{dl})$ & \\
Anemia: $<12$ & $551(40.4)$ \\
Normal: hemoglobin $\geq 12$ & $813(59.6)$ \\
\hline ESRD End-Stage Renal Disease, SD standard deviation
\end{tabular}

grafts), the number of transplantations, the graft rejection episodes and the graft chronic dysfunction.

2. To explore health status and comorbidities: we collected the pathologies frequently associated with KTR (neoplasia, hypertension, and diabetes mellitus), smoking status, Body Mass Index (BMI) and the two validated scales: The Karnofsky Performance Scale (KPS) and The Charlson Comorbidity Index (CCI).

The Karnofsky Performance Scale (KPS) was evaluated to classify patients according to their functional impairment from 0 to $100 \%$. The lower the Karnofsky score, the worse the survival for most serious illnesses was $[23,24]$.

The Charlson Comorbidity Index (CCI) was evaluated to classify patient's comorbidities. According to Charlson et al. [25], the CCI was calculated by assigning for each pathology a score of $1,2,3$, or 6 , depending on the death risk associated with each one and by summing the weights for all present comorbid conditions (ranges from 0 to 37). For the combined age-comorbidity score, each decade of age over 40 adds 1 point to the risk (e.g. 5059 years, 1 point; $60-69$ years, 2 points; $70-79$ years, 3 points...) [26]. Higher scores indicate greater comorbidity.

3. To explore treatments and their side effects, we collected treatment characteristics. We generated with nephrologists a selective list of the most commonly prescribed drugs with their generic names, previously used in a recent publication [27]. This list includes the most used categories of treatments by KTR: immunosuppressive, antihypertensive and other treatments. For each category, we obtained its corresponding drugs. Then, we asked the patients for the existence of side effects related to treatments, without specifying the type.

4. To explore biological data: we collected creatinine and hemoglobin $(\mathrm{Hb})$ levels directly from nephrologists during the medical visit. Creatinine levels were defined by establishing 3 categories with nephrologists (normal $<120 \mu \mathrm{mol} / \mathrm{L}$, mild to moderate: $120-250 \mu \mathrm{mol} / \mathrm{L}$, severe $>250 \mu \mathrm{mol} / \mathrm{L}$ ). 
Anemia was defined by using the World Health Organization (WHO) criteria, which meant that the $\mathrm{Hb}$ concentration was below $12 \mathrm{~g} / \mathrm{dl}$ in women and below $13 \mathrm{~g} / \mathrm{dl}$ in men [28].

\section{Health-related quality of life}

HRQoL was measured with the SF-36 and the ReTransQol. French version of the SF-36 [29, 30] is a generic, self-administered, multidimensional and coherent measure of HRQoL that consists of 36 items, which are used to calculate eight subscales: Physical Functioning (PF), Role Physical (RP), Bodily Pain (BP), General Health $(\mathrm{GH})$, Vitality (VT), Social Functioning (SF), Role Emotional (RE), and Mental Health (MH). The correlated physical (PCS) and mental (MCS) summary components were computed following the standardized procedure provided by authors [27, 31, 32].

The ReTransQol version $2[33,34]$ is a disease specific self-administered instrument assessing the HRQoL of KTR and consisting of 32 items describing 5 dimensions: Physical Health (PH), Mental Health $(\mathrm{MH})$, Medical Care and satisfaction (MC), Treatment (TRT), and Fear of losing the Graft (FG).

Scores for both instruments range from 0 to 100 , with higher scores indicating better HRQoL.

\section{Ethical aspects}

The study methodology was approved by the local Institutional Review Board (CCTIRS n¹2-726) and the
"Comité National Informatique et Liberté" (CNIL n 1639707), thus ensuring the confidentiality of all the collected informations. All patients agreeing to participate signed a written informed consent before their inclusion in the study.

\section{Statistical analysis}

Statistical analysis was performed using Statistical Package for Social Sciences (SPSS) software (version 20, SPSS, Inc., Chicago, IL, USA). Quantitative data were expressed as mean \pm standard deviation (SD), minimum and maximum or median, 25th and 75 th percentiles, whereas categorical data were expressed as frequency and percentage. Group comparisons were performed using analysis of variance (bivariate analysis) for quantitative variables. All factors with a $p$-value $<0.2$ were included as candidate variables in the multivariate analysis. Multivariate Linear Regression models (MLR) were used to estimate the relationship between HRQoL scores and the other characteristics. The $\beta$ coefficients and $p$-value were performed. The level of significance was set at a pvalue $\leq 0.05$. The assumptions of the MLR were verified for linear relationship, normality of distribution, absence of multicollinearity and residuals. Because missing data were minimal $(<10 \%)$, we did not replace them and we only analyzed the available ones (i.e. ignoring the missing data).

Table 3 Clinical characteristics: treatments and their side effects

\begin{tabular}{|c|c|c|}
\hline & $\begin{array}{l}\text { Drugs } \\
N(\%)\end{array}$ & $\begin{array}{l}\text { Side effects } \\
\mathrm{N}(\%)\end{array}$ \\
\hline Mean number of drugs/side effects per patient & $6.6 \pm 1.8(2-14)$ & $6.4 \pm 1.7(4-9)$ \\
\hline Immunosuppressive treatments & $1397(98.1)$ & $344(24.6)$ \\
\hline Calcineurin inhibitors & $1170(82.2)$ & $242(20.6)$ \\
\hline Mycophenolic acid and derivatives & $933(65.5)$ & $115(12.3)$ \\
\hline Corticoids & $832(58.4)$ & $159(19.1)$ \\
\hline Others (mTOR inhibitors, Azathioprine) & $334(23.4)$ & $56(16.7)$ \\
\hline Antihypertensive treatments & $1161(81.5)$ & $72(6.2)$ \\
\hline Beta-blockers & $727(51.1)$ & $28(3.8)$ \\
\hline Angiotensin-converting enzyme (ACE) inhibitors & $709(49.8)$ & $34(4.8)$ \\
\hline Calcium antagonists & $485(34.1)$ & $20(4.1)$ \\
\hline Others (Central antihypertensive, Peripheral vasodilators/alpha-blockers, Diuretics) & $544(38.2)$ & $30(5.5)$ \\
\hline Other treatments & $1170(82.2)$ & $54(4.6)$ \\
\hline Cardiovascular drugs & $792(55.6)$ & $38(48.0)$ \\
\hline Calcium drugs & $727(51.1)$ & $2(0.3)$ \\
\hline Diabetes drugs & $239(16.8)$ & $13(5,4)$ \\
\hline Erythropoiesis-Stimulating Agents (ESA) & $199(14.0)$ & $1(0.5)$ \\
\hline Antidepressants & $149(10.5)$ & $4(2.7)$ \\
\hline
\end{tabular}

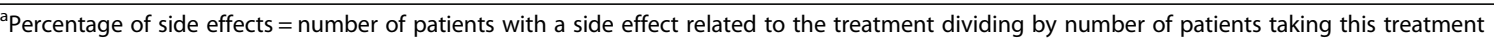




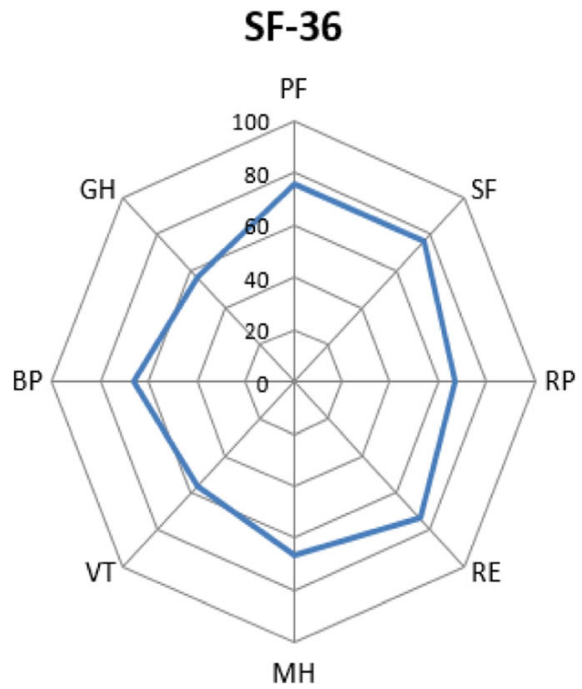

$\mathrm{MH}$
ReTransQol

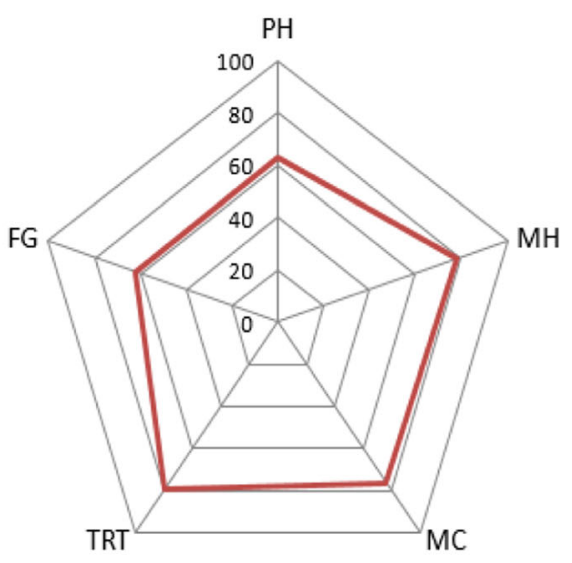

Fig. 1 HRQoL scores (SF36 \& ReTransQol)

\section{Results}

At the time of the survey, 1469 KTR met eligible criteria for the study during 2011. Among them, 45 patients (3.1\%) without QoL questionnaires were excluded from this study and 1424 were included and selected for analysis. Thus, the participation rate is $96.9 \%$.

\section{Patients' characteristics}

As presented in Table 1, patient's mean age was 55.7 years $( \pm 13.1)$, more than $60 \%$ were males and lived with a partner. Less than $40 \%$ attended college and were employed at the time of the survey. The majority of KTR had access to internet in the household. Moreover, most of KTR declared having felt a need for an esteem support more than the other supports.

Regarding the clinical characteristics (Table 2), more than a third of KTR had glomerulonephritis and the majority were dialyzed before transplantation. Median time since transplantation was 7.1 years. Most of patients had a deceased donor transplantation and had a single kidney transplantation. The mean CCI score was 4.09 ( \pm 1.8 , range from 2 to 14 ), and most of KTR had mild to moderate creatinine level (50.8\%). Other characteristics about clinical characteristics are shown in Table 2. Most patients were treated with immunosuppressive drugs. Nearly $28 \%$ of KTR reported side effects related to treatments with a mean number of side effects of $6.4 \pm 1.7$ per patient (Table 3).

\section{Health related quality of life}

Figure 1 shows the mean HRQoL scores and their SD for the eight components of the SF-36 and the five components of the ReTransQol.

\section{Multivariate regression analysis}

We selected all variables in the final regression model for both questionnaires (SF-36 and ReTransQol) according to their significance in the univariate analysis $(p<0.2)$.

Adjusted differences in the ten generic dimensions of SF-36 and in the five specific dimensions of ReTransQol using demographic, psycho-social and clinical variables are shown in Tables 4 and 5 , respectively.

All HRQoL components of SF-36 and RTQ were lower with demographic and clinical characteristics. The variables which contributed most to low QoL scores were receiving disability pension, low monthly incomes and a low Karnofsky Performance Scale $(<70 \%)$. To a lesser extent, advanced age, female gender, having children, unemployment, living alone, a high Charlson Comorbidity Index, high creatinine levels $(>250 \mu \mathrm{mol} / \mathrm{L})$, chronic graft dysfunction, being treated with cardiovascular drugs and presence of side effects related to treatments were associated with low QoL scores (Tables 4 and 5).

Psycho-social variables were also found to be associated with HRQoL scores for both questionnaires. Perceived poor social support and being treated by antidepressants were associated with low scores of QoL, while internet access was associated with high QoL scores (Tables 4 and 5).

\section{Discussion}

This study analyzed the factors associated with HRQoL in a representative sample of 1424 Kideny Transplant Recipients (KTR) from five kidney centers of France. This study goes further from a previous work published in a French national study of 1061 KTR from 8 regions of France, which was the first French report about 
Table 4 Final regression models for SF-36 domains

\begin{tabular}{|c|c|c|c|}
\hline Dimensions & Variables & $\beta$ coeff. $[95 \% \mathrm{Cl}]$ & $P$ values \\
\hline \multirow{14}{*}{$\begin{array}{l}\mathrm{PF} \\
N=1253 \\
R^{2}=0.21\end{array}$} & Intercept & $84.1[75.3 ; 92.8]$ & $<0.001$ \\
\hline & Age & $-0.3[-0.4 ;-0.1]$ & $<0.001$ \\
\hline & Female & $-4.4[-7.0 ;-1.8]$ & 0.001 \\
\hline & Disability pension & $-6.3[-9.0 ;-3.7]$ & $<0.001$ \\
\hline & High monthly incomes $(€)$ & $3.5[2.3 ; 4.7]$ & $<0.001$ \\
\hline & Having felt a need for an esteem support & $-4.1[-6.8 ;-1.3]$ & 0.004 \\
\hline & Having felt a need for a financial support & $-3.1[-6.1 ;-0.1]$ & 0.04 \\
\hline & Diabetic patient & $-4.5[-7.9 ;-1.2]$ & 0.008 \\
\hline & $\mathrm{BMI}>30\left(\mathrm{~kg} / \mathrm{m}^{2}\right)$ & $-4.0[-7.4 ;-0.6]$ & 0.021 \\
\hline & Treatment with ESA & $-3.7[-7.3 ;-0.1]$ & 0.045 \\
\hline & Treatment with antidepressants & $-5.7[-9.7 ;-1.7]$ & 0.005 \\
\hline & $K P S \geq 70 \%$ & $16.9[11.6 ; 22.2]$ & $<0.001$ \\
\hline & High creatinine levels > 250 ( $\mu \mathrm{mol} / \mathrm{L})$ & $-2.7[-4.8 ;-0.6]$ & 0.012 \\
\hline & CCl score & $-1.4[-2.4 ;-0.4]$ & 0.005 \\
\hline \multirow{11}{*}{$\begin{array}{l}\mathrm{RP} \\
N=1256 \\
R^{2}=0.14\end{array}$} & Intercept & $84.0[69.0 ; 99.0]$ & $<0.001$ \\
\hline & Age & $-0.4[-0.5 ;-0.2]$ & $<0.001$ \\
\hline & Disability pension & $-7.4[-12.0 ;-2.7]$ & 0.002 \\
\hline & High monthly incomes $(€)$ & $4.5[2.5 ; 6.5]$ & $<0.001$ \\
\hline & Having felt a need for an esteem support & $-6.4[-11.5 ;-1.3]$ & 0.015 \\
\hline & Having felt a need for an emotional support & $-8.4[-13.6 ;-3.3]$ & 0.001 \\
\hline & Diabetic patient & $-6.2[-11.7 ;-0.8]$ & 0.026 \\
\hline & Treatment with ESA & $-8.9[-15.0 ;-2.7]$ & 0.005 \\
\hline & Treatment with antidepressants & $-15.2[-22.2 ;-8.2]$ & $<0.001$ \\
\hline & $K P S \geq 70 \%$ & $14.6[5.5 ; 23.6]$ & 0.002 \\
\hline & High creatinine levels $>250(\mu \mathrm{mol} / \mathrm{L})$ & $-5.9[-9.4 ;-2.4]$ & 0.001 \\
\hline \multirow{13}{*}{$\begin{array}{l}B P \\
N=1257 \\
R^{2}=0.15\end{array}$} & Intercept & $85.3[74.7 ; 95.9]$ & $<0.001$ \\
\hline & Age & $-0.3[-0.4 ;-0.2]$ & $<0.001$ \\
\hline & Female & $-4.6[-7.7 ;-1.5]$ & 0.003 \\
\hline & Having children & $-3.9[-7.4 ;-0.4]$ & 0.03 \\
\hline & Disability pension & $-6.3[-9.5 ;-3.1]$ & $<0.001$ \\
\hline & High monthly incomes $(€)$ & $1.8[1.4 ; 3.3]$ & 0.014 \\
\hline & Having felt a need for an esteem support & $-5.2[-8.5 ;-1.9]$ & 0.002 \\
\hline & Diabetic patient & $-6.0[-9.8 ;-2.2]$ & 0.002 \\
\hline & Treatment with cardiovascular drugs & $-3.8[-6.9 ;-0.7]$ & 0.017 \\
\hline & Treatment with antidepressants & $-9.6[-14.4 ;-4.7]$ & $<0.001$ \\
\hline & Side effects related to any treatment & $-5.8[-9.0 ;-2.5]$ & $<0.001$ \\
\hline & $K P S \geq 70 \%$ & $14.2[7.9 ; 20.5]$ & $<0.001$ \\
\hline & $\mathrm{CCl}$ score & $-2.7[-5.2 ;-0.3]$ & 0.030 \\
\hline \multirow{6}{*}{$\begin{array}{l}\mathrm{GH} \\
N=1321 \\
R^{2}=0.15\end{array}$} & Intercept & $63.9[58.4 ; 69.4]$ & $<0.001$ \\
\hline & Living alone & $-3.8[-6.4 ;-1.2]$ & 0.004 \\
\hline & Disability pension & $-6.0[-8.3 ;-3.7]$ & $<0.001$ \\
\hline & Having felt a need for an esteem support & $-4.3[-6.9 ;-1.6]$ & 0.002 \\
\hline & Having felt a need for an emotional support & $-3.2[-5.9 ;-0.6]$ & 0.016 \\
\hline & Duration of transplantation & $-0.2[-0.3 ;-0.0]$ & 0.03 \\
\hline
\end{tabular}


Table 4 Final regression models for SF-36 domains (Continued)

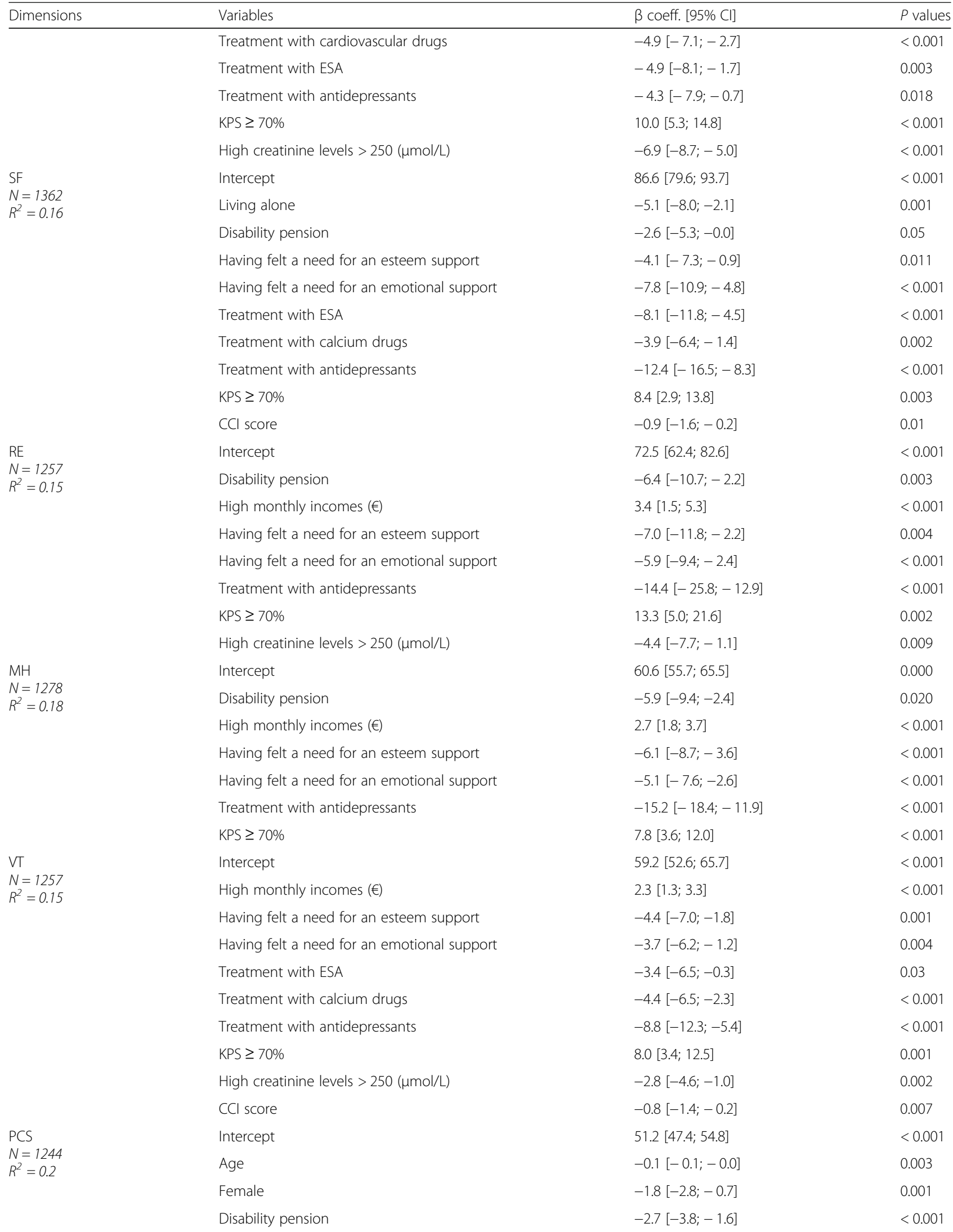


Table 4 Final regression models for SF-36 domains (Continued)

\begin{tabular}{|c|c|c|c|}
\hline Dimensions & Variables & $\beta$ coeff. $[95 \% \mathrm{Cl}]$ & $P$ values \\
\hline \multirow{14}{*}{$\begin{array}{l}\text { MCS } \\
N=1268 \\
R^{2}=0.18\end{array}$} & High monthly incomes $(€)$ & $-0.9[-0.4 ;-1.3]$ & $<0.001$ \\
\hline & Treatment with diabetic drugs & $-2.5[-3.9 ;-1.1]$ & $<0.001$ \\
\hline & Treatment with cardiovascular drugs & $-1.4[-2.4 ;-0.3]$ & 0.009 \\
\hline & Side effects related to any treatment & $-1.4[-2.5 ;-0.3]$ & 0.012 \\
\hline & $K P S \geq 70 \%$ & $5.9[3.7 ; 8.0]$ & $<0.001$ \\
\hline & High creatinine levels > 250 ( $\mu \mathrm{mol} / \mathrm{L})$ & $-2.1[-3.0 ;-1.3]$ & $<0.001$ \\
\hline & $\mathrm{CCl}$ score & $-0.7[-1.1 ;-0.3]$ & 0.001 \\
\hline & Intercept & $49.6[47.9 ; 51.2]$ & $<0.001$ \\
\hline & High monthly incomes $(€)$ & $1.3[0.8 ; 1.8]$ & $<0.001$ \\
\hline & Having felt a need for an esteem support & $-2.8[-4.1 ;-1.4]$ & $<0.001$ \\
\hline & Having felt a need for an emotional support & $-4.0[-5.4 ;-2.7]$ & $<0.001$ \\
\hline & Treatment with calcium drugs & $-1.1[-2.2 ;-0.0]$ & 0.044 \\
\hline & Treatment with antidepressants & $-7.3[-9.1 ;-5.5]$ & $<0.001$ \\
\hline & High creatinine levels > 250 ( $\mu \mathrm{mol} / \mathrm{L})$ & $-1.1[-2.0 ;-0.2]$ & 0.015 \\
\hline
\end{tabular}

$\beta$ coeff $\beta$ coefficient, ESA Erythropoiesis-Stimulating Agent, KPS Karnofsky Performance Scale, CCI Charlson Comorbidity Index, PF Physical Functioning, RP Role Physical, BP Bodily Pain, GH General Health, VT Vitality, SF Social Functioning, RE Role Emotional, MH Mental Health, PCS Physical Component Score, MCS Mental Component Score

HRQoL in kidney transplantation [27]. We analyzed the exploration of psycho-social factors that were poorly studied in literature, such as perceived social support measured by a validated questionnaire [22] and internet access. Indeed, there is growing evidence for the necessity of specifying psychological dimension's influence on quality of life after kidney transplantation [35, 36].

In our study, HRQoL scores, socio-demographic and clinical characteristics of KTR are similar to a French national survey [27]. Socio-demographic variables had a negative influence on HRQoL: level of HRQoL significantly decreases with age, female gender, living status and the educational level. These findings are in accordance with other studies [27, 37-52].

This study points out that KTR receiving a disability pension have an extremely impaired HRQoL, especially for physical dimensions. This association may be influenced by the impact of manual work [53]. Patients in lower-ranked occupations may have less control in the work situation and thereby less possibility to prevent their health influenced by physical demands and poor ergonomic working environment [54].

Karnofsky Performance Status (KPS) was strongly associated with good HRQoL scores, whatever the instrument used. Whether KTR could carry normal activity and take care of themselves are the important parameters of measurement of QoL. Zhang L et al. [55] suggested that KPS score could be the most important factor associated with QoL values in patients with advanced HIV. These results suggest that healthy lifestyle and physical function are recommended after transplantation to improve HRQoL and it seems important to counsel and encourage for more physical activity as a part of routine medical care in KTR.

Furthermore, treatments with diabetic, cardiovascular and calcium drugs had a negative impact on HRQoL, especially for physical dimensions. In contrast, we did not find any association between immunosuppressive drugs and HRQoL, which suggests that nephrologists should use more effective treatments to prevent rejection and preserve the kidney function without adversely affecting HRQoL. A specific health education for KTR, including how treatments must be adhered, its benefits and side effects, is also recommended for KTR to handle difficulties due to specific treatments.

We also found a strong association between antidepressants and bad HRQoL scores for both physical and mental components. It is possible that patients treated with antidepressants tended to somatize more and give more emphasis to the negative effects of transplantation than its positive effects $[56,57]$. It could also suggest that patients with worse health conditions are more susceptible to depression, even after transplantation. Studies reported that patients undergoing dialysis and/or transplantation, may become unable to cope with it, as it affects their mind integrity [58]. Depression and anxiety as impaired HRQoL are known to be associated with increased mortality and poor outcomes in $\operatorname{KTR}[59,60]$. Mental health is thus playing an important role in HRQoL and should not be underestimated after kidney transplantation.

Aside from these factors, social support was significantly associated with bad HRQoL scores. KTR with a need for an esteem and emotional support have bad 
Table 5 Final regression models for ReTransQol domains

\begin{tabular}{|c|c|c|c|}
\hline Dimensions & Variables & $\beta$ coeff. $[95 \% \mathrm{Cl}]$ & $P$ values \\
\hline \multirow{10}{*}{$\begin{array}{l}\mathrm{PH} \\
N=1340 \\
R^{2}=0.1\end{array}$} & Intercept & $65.2[61.3 ; 69.0]$ & $<0.001$ \\
\hline & Employment status & $2.1[0.6 ; 3.5]$ & 0.005 \\
\hline & Disability pension & $-2.8[-4.2 ;-1.5]$ & $<0.001$ \\
\hline & Having felt a need for an esteem support & $-3.1[-4.6 ;-1.6]$ & $<0.001$ \\
\hline & Having felt a need for an emotional support & $-1.7[-3.3 ;-0.2]$ & 0.022 \\
\hline & Treatment with cardiovascular drugs & $-1.7[-3.0 ;-0.4]$ & 0.009 \\
\hline & Treatment with antidepressants & $-4.2[-6.2 ;-2.1]$ & $<0.001$ \\
\hline & Side effects related to any treatment & $-1.4[-2.8 ;-0.07]$ & 0.04 \\
\hline & $K P S \geq 70 \%$ & $5.4[2.6 ; 8.1]$ & $<0.001$ \\
\hline & High creatinine levels > 250 ( $\mu \mathrm{mol} / \mathrm{L})$ & $-1.5[-2.6 ;-0.5]$ & 0.003 \\
\hline \multirow{8}{*}{$\begin{array}{l}\mathrm{MH} \\
N=1276 \\
R^{2}=0.1\end{array}$} & Intercept & $77.5[73.7 ; 81.4]$ & $<0.001$ \\
\hline & Female & $-2.0[-3.8 ;-0.1]$ & 0.034 \\
\hline & Living alone & $-5.1[-7.3 ;-3.0]$ & $<0.001$ \\
\hline & Disability pension & $-2.3[-4.3 ;-0.4]$ & 0.015 \\
\hline & High monthly incomes $(€)$ & $1.4[0.5 ; 2.4]$ & 0.002 \\
\hline & Internet use & $5.4[0.2 ; 5.0]$ & 0.03 \\
\hline & Having felt a need for an informative support & $2.1[0.2 ; 3.8]$ & 0.024 \\
\hline & Treatment with antidepressants & $-7.0[-9.8 ;-4.0]$ & $<0.001$ \\
\hline \multirow{5}{*}{$\begin{array}{l}M C \\
N=1355 \\
R^{2}=0.1\end{array}$} & Intercept & $78.2[76.9 ; 79.6]$ & $<0.001$ \\
\hline & Having felt a need for an informative support & $1.9[0.5 ; 3.4]$ & 0.008 \\
\hline & Treatment with ESA & $-7.0[-9.8 ;-4.0]$ & 0.06 \\
\hline & Treatment with calcium drugs & $-2.3[-3.7 ;-0.8]$ & 0.001 \\
\hline & High creatinine levels > 250 ( $\mu \mathrm{mol} / \mathrm{L})$ & $-2.0[-3.1 ;-0.7]$ & 0.002 \\
\hline \multirow{8}{*}{$\begin{array}{l}\text { TRT } \\
N=1347 \\
R^{2}=0.1\end{array}$} & Intercept & $86.8[82.2 ; 91.5]$ & $<0.001$ \\
\hline & High educational level & $-3.4[-6.1 ;-0.7]$ & 0.011 \\
\hline & Having felt a need for an esteem support & $-4.2[-6.3 ;-2.1]$ & $<0.001$ \\
\hline & Having felt a need for an informative support & $-3.1[-5.2 ;-1.1]$ & 0.003 \\
\hline & Treatment with calcium drugs & $-2.2[-4.0 ;-0.5]$ & 0.011 \\
\hline & Side effects related to any treatment & $-2.2[-4.1 ;-0.3]$ & 0.023 \\
\hline & $K P S \geq 70 \%$ & $4.1[0.4 ; 7.7]$ & 0.026 \\
\hline & High creatinine levels > 250 ( $\mu \mathrm{mol} / \mathrm{L})$ & $-3.1[-4.5 ;-1.8]$ & $<0.001$ \\
\hline \multirow{8}{*}{$\begin{array}{l}F G \\
N=1259 \\
R^{2}=0.1\end{array}$} & Intercept & $70.4[66.1 ; 74.4]$ & $<0.001$ \\
\hline & Disability pension & $-4.0[-6.2 ;-1.7]$ & 0.001 \\
\hline & High monthly incomes $(€)$ & $1.9[0.4 ; 2.9]$ & $<0.001$ \\
\hline & Having felt a need for an esteem support & $-4.1[-6.7 ;-1.6]$ & 0.001 \\
\hline & Having felt a need for an emotional support & $-3.7[-6.3 ;-1.2]$ & 0.004 \\
\hline & Being on dialysis before transplantation & $-4.8[-7.8 ;-1.7]$ & 0.002 \\
\hline & Treatment with antidepressants & $-3.6[-7.0 ;-0.2]$ & 0.037 \\
\hline & High creatinine levels > 250 ( $\mu \mathrm{mol} / \mathrm{L})$ & $-3.7[-5.9 ;-2.1]$ & $<0.001$ \\
\hline
\end{tabular}

$\beta$ coeff $\beta$ coefficient, ESA Erythropoiesis-Stimulating Agent, KPS Karnofsky Performance Scale, PH Physical Health, MH Mental Health, MC Medical Care and satisfaction, TRT Treatment, FG Fear of losing the Graft

QoL scores in almost all dimensions and specifically in mental dimensions (Tables 4 and 5). This underlies that social support may reflect non-constructive coping strategies with the disease, which should not be underestimated. Furthermore, informative support and internet access were associated with high QoL scores for mental dimension of ReTransQol (Table 5), testifying their interest in seeking for information and 
communication about their health or their transplant, and arguing the need for progress in these fields. These results are in accordance with previous studies, which demonstrated that Internet could improve the wellbeing and QoL by providing mental stimulation and challenge [61].

Summing up, these new findings reinforce the importance of patients' psychological health and strengthen the necessity of psychosocial development and support for these patients. Our patients may, after kidney transplantation, need more psychological interventions aiming to provide information about their medical care. This could help them to deal with their disease and reduce several mental problems (such as stress and anxiety). Therefore, for better post-transplant rehabilitation and given the risks of psychopathology, the development of interdisciplinary interventions such as socio-medical and psychotherapeutic programs are essential.

Finally, our sample is representative of general French KTR with a large sample size. To our knowledge, there are few studies with a sample over 1000 patients [17, 62, 63]. Another strong point of the current study was the use of generic and specific HRQoL tools. We applied the generic instrument SF-36 Health Survey [29, 30], the most used questionnaire for HRQoL analysis in KTR [64-67], and a disease-specific instrument validated for KTR in the French language: the ReTransQol version 2 [34]. Both questionnaires are very interesting to work with, as they are complementary and offer different views on the global aspects and the specific domains to identify factors associated with HRQoL for KTR. Indeed, RTQ was more sensitive than SF-36 for clinical variables such as treatment and fear of losing the graft, but less exhaustive for demographic factors. Another strong point of this study was the construction of a comprehensive multivariate model, including many variables, especially psycho-social ones that were poorly studied in QoL studies for KTR. Despite being comprehensive, the final regression models explained $20 \%$ of the physical (PCS) HRQoL variance and $18 \%$ of mental HRQoL variance (MCS). Limitations of our research are related to the cross-sectional design, which is the first phase of our longitudinal study, so we cannot truly interpret predictive factors. The longitudinal data are currently under analysis to compare HRQoL scores, its evolution over time and its associated factors.

\section{Conclusion}

The originality of our study's findings was that new variables, particularly KTR treated by antidepressants and having felt unmet needs for any social support, have a negative effect on their QoL. It may be useful to organize a psychological support specifically adapted for these patients. In order to orientate psychological programs and improve patient care and well-being, a better understanding of how patients anticipate, live and face post-kidney-transplantation and a deep investigation of psychological factors are needed in future QoL studies.

\section{Abbreviations \\ BMI: Body Mass Index; BP: Bodily Pain; CCl: Charlson Comorbidity Index; ESA: Erythropoiesis-Stimulating Agents; ESRD: End-Stage Renal Disease; FG: Fear of losing the Graft; GH: General Health; Hb: Hemoglobin; HRQoL: Health-Related Quality of Life; KPS: Karnofsky Performance Scale; KTR: Kidney Transplant Recipients; MC: Medical Care and satisfaction; MCS: Mental Composite Score; MH: Mental Health; MLR: Multivariate Linear Regression; PCS: Physical Composite Score; PF: Physical Functioning; PH: Physical Health; QoL: Quality of Life; RE: Role Emotional; RP: Role Physical; RTQ: ReTransQol; SD: Standard Deviation; SF: Social Functioning; SF-36: Short Form-36 Health Survey; TRT: Treatment; VT: Vitality; WHO: World Health Organization; $\beta$ coeff: $\beta$ coefficient}

\section{Acknowledgements}

The authors would like to thank patients, nephrologists and clinical technicians for their help and participation to this study.

\section{Funding}

This study is integrated in a research program funded by: Direction Générale de l'Offre de Soins, Ministère des affaires sociales et de la santé, for study design and data collection. Authors declare that they have no conflicts of interest regarding this funding source. Analysis, interpretation of data and writing of the manuscript were not associated with any funding.

\section{Availability of data and materials}

All data generated or analyzed during this study are included in this article. The datasets of this study are not publicly available at present. As it is a longitudinal study, all data are under analysis for the publication of other articles/studies, but they can be available from the corresponding author on reasonable request.

\section{Authors' contributions}

YM performed statistical analysis, analyzed and interpreted the data and drafted the manuscript; SG conceived the study and its design, coordinated the data management, interpreted the data and revised the manuscript critically; EJ participated in the statistical analysis; MA and NP revised the manuscript; $B D, V M, A M, E C, G M$ and $A D$ participated in the design of the study, collected medical data and participated to the interpretation of data. All authors read and approved the final manuscript.

\section{Ethics approval and consent to participate}

The study methodology was approved by the local Institutional Review Board (CCTIRS n 12-726) and the "Comité National Informatique et Liberté" (CNIL n¹639707), thus ensuring the confidentiality of all the collected informations. All patients agreeing to participate signed a written informed consent before their inclusion in the study.

\section{Competing interests}

The authors declare that they have no competing interests.

\section{Publisher's Note}

Springer Nature remains neutral with regard to jurisdictional claims in published maps and institutional affiliations.

\section{Author details}

'Laboratoire de Santé Publique, Faculté de Médecine, Université Aix-Marseille, 3279 Marseille, EA, France. ${ }^{2}$ Service Santé Publique et Information Médicale, CHU Marseille, Marseille, France. ${ }^{3}$ Centre de Néphrologie et de Transplantation Rénale, CHU Marseille, Marseille, France. ${ }^{4}$ Transplantation, Urology and Nephrology Institute (ITUN), CHU Nantes, Nantes, France. ${ }^{5}$ Hôpital Pasteur, Nice, France. ${ }^{6}$ Département de Néphrologie, Dialyse et Transplantation, CHU Montpellier, Montpellier, France. ${ }^{7}$ Service de Néphrologie, CHU Bicêtre, Paris, France. 


\section{Received: 22 June 2017 Accepted: 11 April 2018}

\section{Published online: 27 April 2018}

\section{References}

1. Finkelstein FO, Wuerth D, Finkelstein SH. Health related quality of life and the CKD patient: challenges for the nephrology community. Kidney Int. 2009;76(9):946-52

2. Aarnio M, Winter T, Kujala U, Kaprio J. Associations of health related behaviour, social relationships, and health status with persistent physical activity and inactivity: a study of Finnish adolescent twins. Br J Sports Med. 2002;36(5):360-4.

3. Revicki DA, Kleinman L, Cella D. A history of health-related quality of life outcomes in psychiatry. Dialogues Clin Neurosci. 2014;16(2):127-35.

4. Guyatt GH, Feeny DH, Patrick DL. Measuring health-related quality of life. Ann Intern Med. 1993;118:622-9.

5. Loria A, Escheik C, Gerber NL, Younossi ZM. Quality of life in cirrhosis. Curr Gastroenterol Rep. 2013;15:301.

6. Strong K, Mathers C, Leeder S, Beaglehole R. Preventing chronic diseases: how many lives can we save? Lancet. 2005;366:1578-82.

7. WHO: Preventing chronic disease prevention: a vital investment [Internet] http://www.who.int/chp/chronic_disease_report/part1/fr/index16.html.

8. Law $n^{\circ} 2004-806$ of 9 August 2004 relating to public health policy | Legifrance [Internet], http://www.legifrance.gouv.fr/affichTexte.docidTexte= JORFTEXT000000787078\&dateTexte=\&categorieLien=id.

9. Jungers P, Choukroun G, Robino C, Massy ZA, Taupin P, Labrunie M, et al. Epidemiology of end-stage renal disease in the lle-de-France area: a prospective study in 1998. Nephrol Dial Transplant. 2000;15(12):2000-6.

10. Labeeuw M. Treatment of end stage renal failure by dialysis in RhôneAlpes. Changes over the period 1993-1999. Nephrologie. 2001;22(4):161-6.

11. Finnegan-John J, Thomas Veronica J. The psychosocial experience of patients with end-stage renal disease and its impact on quality of life: findings from a needs assessment to shape a service. ISRN Nephrology. 2013; https://doi.org/10.5402/2013/308986

12. Avramovic M, Stefanovic $V$. Health-related quality of life in different stages of renal failure. Artif Organs. 2012;36:581-9.

13. Laupacis A, Keown P, Pus N, Krueger H, Ferguson B, Wong C, et al. A study of quality of life and cost-utility of renal transplantation. Kidney Int. 1996;50:235-42.

14. Wolfe RA, Ashby VB, et al. Comparison of mortality in all patients on dialysis, patients on dialysis awaiting transplantation, and recipients of a first cadaveric transplant. N Engl J Med. 1999:341:1725-30.

15. Sesso R, Eisenberg JM, Stabile C, Draibe S, Ajzen H, et al. Cost-effectiveness analysis of the treatment of end-stage renal disease in Brazil. Int J Technol Assess Health Care. 2009;6(1):107-14.

16. Evans RW, Kitzmann DJ. An economic analysis of kidney transplantation. Surg Clin N Am. 1998;78:149-74.

17. Jofré R, López-Gómez JM, Moreno F, Sanz-Guajardo D, Valderrábano F. Changes in quality of life after renal transplantation. Am J Kidney Dis. 1998; 32(1):93-100.

18. Van der Mei SF, Groothoff JW, van Sonderen ELP, van den Heuvel WJA, de Jong PE, van Son WJ. Clinical factors influencing participation in society after successful kidney transplantation. Transplantation. 2006;82(1):80-5.

19. Liem YS, Bosch JL, Arends LR, Heijenbrok-Kal MH, et al. Quality of life assessed with the medical outcomes study short form 36-item health survey of patients on renal replacement therapy: a systematic review and meta-analysis. Value Health. 2007;10(5):390-7.

20. Maglakelidze N, Pantsulaia T, Tchokhonelidze I, Managadze L, Chkhotua A. Assessment of health-related quality of life in renal transplant recipients and dialysis patients. Transplant Proc. 2011;43(1):376-9.

21. Tonelli M, Wiebe N, Knoll G, Bello A, Browne S, Jadhav D, et al. Systematic review: kidney transplantation compared with dialysis in clinically relevant outcomes. Am J Transplant. 2011;11(10):2093-109.

22. Bruchon-Schweitzer M, Quintard B. Personality and illness. Stress, adaptation and adjustment. Paris: Ed Dubod; 2001.

23. Karnofsky DA, Burcherval JH. The clinical evaluation of chemotherapeutic agents in cancer. In: Macleod CM, editor. Evaluation of chemotherapeutic agents. New York: Columbia University Press; 1949. p. 191-205.

24. Schag CC, Heinrich RL, Ganz PA. Karnofsky performance status revisited: reliability, validity, and guidelines. J Clin Oncol. 1984;2:187-93.

25. Charlson ME, Pompei P, Ales KL, MacKenzie CR. A new method of classifying prognostic comorbidity in longitudinal studies: development and validation. J Chronic Dis. 1987;40(5):373-83.
26. Charlson M, Szatrowski TP, Peterson J, Gold J. Validation of a combined comorbidity index. J Clin Epidemiol. 1994;47(11):1245-51.

27. Gentile S, Beauger D, Speyer E, Jouve E, Dussol B, Jacquelinet C, et al. Factors associated with health-related quality of life in renal transplant recipients: results of a national survey in France. Health Qual Life Outcomes. 2013;11(1):88

28. Organization WH: Nutritional Anemia: report of a WHO scientific group (technical report series n. 405). 1968.

29. Ware JE, Sherbourne CD. The MOS 36-item short-form health survey (SF-36) I. Conceptual framework and item selection. Med Care. 1992;30:473-83.

30. Leplège A, Coste J. Introduction, enjeux, définitions : Mesure de la santé perceptuelle et de la qualité de vie: méthodes et applications. In: Estem; 2002. p. 15-36.

31. Ware JE. SF-36 physical and mental health summary scales: a user's manual. Boston: Health Assessment Lab. New England Medical Center; 1994.

32. Farivar SS, Cunningham WE, et al. Correlated physical and mental health summary scores for the SF-36 and SF-12 health survey, V.1. Health Qual Life Outcomes. 2007;5:54.

33. Gentile S, Jouve E, Dussol B, Moal V, Berland Y, Sambuc R. Development and validation of a French patient-based health-related quality of life instrument in kidney transplant: the ReTransQoL. Health Qual Life Outcomes. 2008;(1):78.

34. Beauger D, Gentile $\mathrm{S}$, Jouve $\mathrm{E}$, et al. Analysis, evaluation and adaptation of the ReTransQoL: a specific quality of life questionnaire for renal transplant recipients. Health Qual Life Outcomes. 2013;11:148.

35. Kim W, Kreps GL, Shin C-N. The role of social support and social networks in health information-seeking behavior among Korean Americans: a qualitative study. Int J Equity Health. 2015;14:40. https://doi.org/10.1186/ s12939-015-0169-8.

36. De Pasquale C, Veroux M, Indelicato L, et al. Psychopathological aspects of kidney transplantation: efficacy of a multidisciplinary team. World J Transplant. 2014:4(4):267-75.

37. Ponton P, Rupolo GP, Marchini F, Feltrin A, Perin N, Mazzoldi MA, et al. Quality-of-life change after kidney transplantation. Transplant Proc. 2001; 33(1-2):1887-9.

38. Chiu SFA, Wong HS, Morad Z, et al. Quality of life in cadaver and livingrelated renal transplant recipient in Kuala Lumpur hospital. Transplant Proc. 2004;36:2030-1.

39. Fiebiger W, Mitterbauer C, Oberbauer R. Health-related quality of life outcomes after kidney transplantation. Health Qual Life Outcomes. 2004;2:2.

40. Ogutmen B, Yildirim A, Sever MS, Bozfakioglu S, Ataman R, Erek E, et al. Health-related quality of life after kidney transplantation in comparison intermittent hemodialysis, peritoneal dialysis, and normal controls. Transplant Proc. 2006;38(2):419-21.

41. Khedmat H, Karami GR, Pourfarziani V, Assari S, Rezailashkajani M, et al. A logistic regression model for predicting health-related quality of life in kidney transplant recipients. Transplant Proc. 2007;39:917-22.

42. Bohlke M, Marini SS, Rocha M, Terhorst L, Gomes RH, Barcellos FC, et al. Factors associated with health-related quality of life after successful kidney transplantation: a population-based study. Qual Life Res. 2009;18(9):1185-93.

43. Rambod M, Shabani M, Shokrpour N, Rafii F, Mohammadalliha J. Quality of life of hemodialysis and renal transplantation patients. Health Care Manag (Frederick). 2011;30(1):23-8.

44. Stavem K, Ganss R. Reliability and validity of the ESRD symptom checklisttransplantation module in Norwegian kidney transplant recipients. BMC Nephrol. 2006;7:17.

45. Molnar-Varga M, Molnar MZ, Szeifert L, Kovacs AZ, Kelemen A, Becze A, et al. Health-related quality of life and clinical outcomes in kidney transplant recipients. Am J Kidney Dis. 2011;58(3):444-52.

46. Rebollo P, Ortega F, Baltar JM, Díaz-Corte C, Navascués RA, Naves M, et al. Health-related quality of life (HRQOL) in end stage renal disease (ESRD) patients over 65 years. Geriatr Nephrol Urol. 1998;8(2):85-94.

47. Keogh AM, Feehally J. A quantitative study comparing adjustment and acceptance of illness in adults on renal replacement therapy. ANNA J. 1999; 26:471-7.

48. Rosenberger J, van Dijk JP, Nagyova I, Zezula I, Geckova AM, Roland R, et al. Predictors of perceived health status in patients after kidney transplantation. Transplantation. 2006;81(9):1306-10.

49. Lubetkin El, Jia H, Franks P, Gold MR. Relationship among sociodemographic factors, clinical conditions, and health-related quality of life: examining the EQ-5D in the US general population. Qual Life Res. 2005;14:2187-96. 
50. Johnson CD, Wicks MN, Milstead J, Hartwig M, et al. Racial and gender differences in quality of life following kidney transplantation. J Nurs Scholarsh. 1998;30:125-30.

51. Kontodimopoulos N, Pappa E, Niakas D. Gender- and age-related benefit of renal replacement therapy on health-related quality of life. Scand I Caring Sci. 2009;23:721-9.

52. Fructuoso M, Castro R, Oliveira L, Prata C, Morgado T. Quality of life in chronic kidney disease. Nefrologia. 2011;31(1):91-6.

53. Krokstad S, Johnsen R, Westin S. Social determinants of disability pension: a 10-year follow-up of 62000 people in a Norwegian county population. Int J Epidemiol. 2002;31:1183-91. https://doi.org/10.1093/ije/31.6.1183.

54. Lahelma E, Laaksonen M, Lallukka T, Martikainen P, Pietilainen O, Saastamoinen P, Gould R, Rahkonen O. Working conditions as risk factors for disability retirement: a longitudinal register linkage study. BMC Public Health. 2012;12:309. https://doi.org/10.1186/1471-2458-12-309.

55. Zhang L, Yang B, Zhang J. Related factors associated with quality of life assessed using a Chinese version of the MOS-HIV health survey in people with HIV/AIDS in China. J AIDS Clin Res. 2016;7:568. https://doi.org/10.4172/ 2155-6113.1000568.

56. Levy NB. Psychological aspects of renal transplantation. Psychosomatics. 1994;35:427-33.

57. Brickman AL, Rothber ST, Yount SE, Blaney NT, Morgan R. Is satisfaction with kidney transplantation influenced by personality and post-transplant sideeffects? Dial Transplant. 1998;27:725-33.

58. Knight EL, Otsthun N, Teng M, et al. The association between mental health, physical function and haemodialysis mortality. Kidney Int. 2003;63:1843-51.

59. Jana AK, Sircar D, Waikhom R, et al. Depression and anxiety as potential correlates of post-transplantation renal function and quality of life. Indian J Nephrol. 2014;24(5):286-90.

60. Müller HH, Englbrecht M, Wiesener MS, et al. Depression, anxiety, resilience and coping pre and post kidney transplantation - initial findings from the psychiatric impairments in kidney transplantation (PI-KT)-study. Bueno V. PLoS One. 2015;10(11)

61. Slegers K, Van Boxtel MPJ, Jolles J. Effects of computer training and internet usage on the well-being and quality of life of older adults: a randomized, controlled study. J Gerontol Ser B-Psychol Sci Soc Sci. 2008;63:176-84.

62. Wight JP, Edwards L, Brazier J, Walters S, Payne JN, et al. The SF36 as an outcome measure of services for end stage renal failure. Qual Health Care. 1998;209(4):209-21.

63. Ichikawa Y, Fujisawa M, Hirose E, Kageyama T, Miyamoto Y, Sakai Y, et al. Quality of life in kidney transplant patients. Transplant Proc. 2000;32(7): 1815-6.

64. Humar A, Denny R, Matas AJ, Najarian JS. Graft and quality of life outcomes in older recipients of a kidney transplant. Exp Clin Transplant. 2003;1 (2):69-72.

65. Matas AJ, McHugh L, Payne WD, Wrenshall LE, Dunn DL, Gruessner RW. Long-term quality of life after kidney and simultaneous pancreas-kidney transplantation. Clin Transpl. 1998;12(3):233-42.

66. Butt Z, Yount SE, Caicedo JC, Abecassis MM, Cella D. Quality of life assessment in renal transplant: review and future directions. Clin Transpl. 2008;22(3):292-303.

67. Jay CL, Butt Z, Ladner DP, Skaro Al, Abecassis MM. A review of quality of life instruments used in liver transplantation. J Hepatol. 2009;51(5):949-59.

\section{Ready to submit your research? Choose BMC and benefit from:}

- fast, convenient online submission

- thorough peer review by experienced researchers in your field

- rapid publication on acceptance

- support for research data, including large and complex data types

- gold Open Access which fosters wider collaboration and increased citations

- maximum visibility for your research: over $100 \mathrm{M}$ website views per year

At BMC, research is always in progress.

Learn more biomedcentral.com/submissions 